\title{
Discussion: Implementing Planning Policy Statement 6
}

\section{B. J. Simpson}

John Barrell, formerly Test Valley Borough Council

In our democratic society the public, quite rightly and properly, cannot be forced to use a particular means of transport. Therefore they must be encouraged to use a mode that will cause least harm to the environment and the economy, one of the aims of PPS6.

In making any journey, one considers the costs of travel, ease of use, possible encumbrance, frequency and availability of alternatives to one's car, weather and general traffic conditions. If public transport is to compete it must be seen to be convenient, frequent, reliable, comfortable and (particularly) affordable.

One common initiative, the park-and-ride scheme, has been well used in a large town, such as Oxford. However, in many small towns public transport has suffered. Andover (with a population of 40000 ) is served by frequent bus services on several routes within the town and some less frequent services that operate to adjacent towns via intervening villages. While many out of town services are well used, fare increases in excess of inflation have discouraged its use.

A journey of one mile from home to town for two people costs about $£ 1$ each, with a similar cost for a return trip. Assuming one already owns a car, the perceived cost of motoring is about 25-30 pence per mile.

A local authority in a small town dare not risk driving shoppers out by making car park charges prohibitive. As PPS6 recognises, it is important for town centres to retain vitality. It does not take much calculation to show that the car wins.

Bus companies are faced with large bills in replacing their fleets, partly to provide disabled-friendly vehicles to meet the requirements of the Disability Discrimination Act. The responsibilities placed on them by health and safety legislation grow year by year. These and other costs must be recovered, contradicting the need to contain or reduce fares to encourage use by members of the public. I fear that this particular element of PPS6 is doomed to failure. 